\title{
MAI - JUIN 1981
}

630 ANNÉE - N• 720

\section{revue}

internationale

de la

croix-rouge

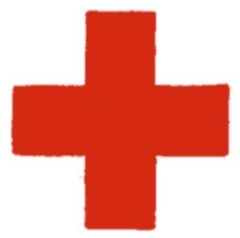

INTER ARMA CARITAS

GENEVE

COMITÉ INTERNATIONAL DE LA CROIX-ROUGE FONDÉ EN 1883 


\title{
COMITÉ INTERNATIONAL DE LA CROIX-ROUGE
}

MM. ALEXANDRE HAY, avocat, ancien directeur général de la Banque nationale suisse, président (membre depuis 1975)

HARALD HƯBER, docteur en droit, juge fédéral, vice-président (1969)

RICHARD PESTALOZZI, docteur en droit, vice-président (1977)

JEAN PICTET, docteur en droit, ancien vice-président du CICR (1967)

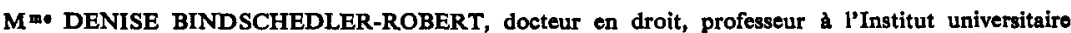
de hautes études internationales, Genève, juge à la Cour européenne des droits de l'homme (1967)

MM. MARCEL A. NAVILLE, licencié ès lettres, président du CICR de 1969 à 1973 (1967)

JACQUES F. DE ROUGEMONT, docteur en médecine (1967)

VICTOR H. UMBRICHT, docteur en droit, administrateur (1970)

GILBERT ETIENNE, professeur à l'Institut universitaire de hautes études internationales et à l'Institut d'études du développement, Genève (1973)

ULRICH MIDDENDORP, docteur en médecine, chef de la clinique chirurgicale de l'Hôpital cantonal, Winterthour (1973)

M'm• MARION BOVÉE-ROTHENBACH, docteur en sociologie (1973)

MM. HANS PETER TSCHUDI, docteur en droit, ancien conseiller fédéral (1973)

HENRY HUGUENIN, banquier (1974)

JAKOB BURCKHARDT, docteur en droit, ministre plenipotentiaire (1975)

THOMAS FLEINER, docteur en droit, professeur à l'Université de Fribourg (1975)

ATHOS GALLINO, docteur en médecine, maire de Bellinzone (1977)

ROBERT KOHLER, docteur ès sciences économiques (1977)

MAURICE AUBERT, docteur en droit, banquier (1979)

RUDOLF JACKLI, docteur ès sciences, géologue (1979)

$M^{\text {ue }}$ ANDREE WEITZEL, ancien chef du service complémentaire féminin au Département militaire fédéral, vice-présidente de la Commission nationale suisse pour l'Unesco (1979)

MM. OLIVIER LONG, docteur en droit et docteur es sciences politiques, ambassadeur, ancien directeur général du GATT (1980)

DIETRICH SCHINDLER, docteur en droit, professeur à l'Université de Zurich (1961-1973; 1980)

\section{CONSEIL EXÉCUTIF}

\author{
M. ALEXANDRE HAY, président \\ M. RICHARD PESTALOZZI \\ M. JAKOB BURCKHARDT \\ M. ATHOS GALLINO \\ M. RUDOLF JACKLI \\ MU• ANDRÉE WEITZEL
}




\section{REVUE INTERNATIONALE DE LA CROIX-ROUGE}

ISSN 0035-3361

SOMMAIRE

COMITE INTERNATIONAL DE LA CROIX-ROUGe

DANS LE MONDE DE LA CROIX-ROUGE

LIVRES ET REVUES
MAI-JUIN $1981-\mathrm{N}^{\circ} 729$

Jacques Moreillon : La solidarité internationale et la protection des détenus politiques . . . . .

André Durand: Le Comité international de la Croix-Rouge (II) . . . . . . . . . . . .

Décès de Lady Angela of Limerick . . . . . . 159

Le Premier ministre de l'Inde en visite au CICR $\quad 161$

Déclaration de succession de Grenade aux Conventions de Genève . . . . . . . . . . 161

Correction apportée au texte du Protocole I . . 162

Activités extérieures :

Afrique - Amérique latine - Asie - MoyenOrient - Europe ......... 163

Conférence régionale à Djakarta . . . . . 178 Le centenaire de la Croix-Rouge hongroise . . 179

Guerre civile et droit international ( $\mathrm{Dr}$ A. V. Lombardi) . . . . . . . . . . . . 185

Berceau de la Croix-Rouge (B. Lescaze) . . 187 
La Revue internationale de la Croix-Rouge est publiée par le Comité international de la Croix-Rouge depuis 1869.

Organe officiel du CICR,

publication spécialisée dans le droit international humanitaire,

chronique des activités internationales de la Croix-Rouge,

la Revue internationale maintient un courant d'informations et constitue le lien nécessaire entre les membres de la Croix-Rouge internationale.

La Revue internationale de la Croix-Rouge parait, une fois tous les deux mois, en trois éditions principales:

en français: RevUe InTERnationale de LA Croix-Rouge

en anglais: INTERNATIONAL ReVIEW OF THE Red Cross (depuis 1961)

en espagnol: Revista INTERNACIONAL DE LA CRUz RoJA (depuis 1976)

Elle publie également, en allemand, un cahier d'Extraits des textes parus dans les éditions principales.

RÉdaction: Michel Testuz

ADRESSE: Revue internationale de la Croix-Rouge

17, avenue de la Paix

CH - 1211 - Genève, Suisse

Abonnements: un an 30 francs suisses; le numéro 5 francs.

Extraits en allemand: un an 10 francs; le numéro 2 francs.

Compte de chèques postaux: 12 - 1767 Genève

Compte bancaire: 129.986 Société de Banque Suisse, Genève

Seuls les textes signés par le Comité international de la Croix-Rouge engagent la responsabilité de celui-ci. 